\title{
High H1N1 prevalence and mortality rates a concern
}

$\mathrm{T}$

ype $A(\mathrm{H} 1 \mathrm{~N} 1)$ influenza, the most common flu virus in Canada this year, has a higher than anticipated mortality rate causing some experts to wonder if it's virulence has increased.

The worrisome factor at this point "is the reported mortality rate in Alberta," says Dr. Pierre Lebel, an infectious disease specialist at the McGill University Health Centre in Montréal, Quebec. As of Jan. 13, there were ten confirmed deaths in Alberta attributed to type A (H1N1) influenza, as well as one in British Columbia, six in Saskatchewan, six in Ontario, one in Quebec and two in Nova Scotia

"There are more deaths than what we expect for the regular H1N1 influenza," says Lebel. The strain this year could be more virulent than in past years, but it's too early to know for sure, he adds. This year's virus is now being sequenced with the aim of detecting mutations that might cause higher levels of virulence.

Regardless, the best protection is vaccination, says Lebel, particularly for those who are at high-risk of developing bad flu. This year's flu shot protects against the type A (H1N1) virus, among others. People who were exposed to H1N1 during the 2009 pandemic, either by acquiring the virus or through immunization, can become infected again owing to slight variations in the virus.

According to the Public Health Agency of Canada (PHAC), 96\% of this year's lab-confirmed influenza is type A (H1N1). The virus is unusual in that it appears to affect younger people more than other strains of seasonal influenza. People aged 20 to 65 are being hit harder than usual, comprising $52 \%$ of flu cases. Normally, $80 \%$ of people who die from seasonal flu are 65 years of age or older, but during the $2009 \mathrm{H} 1 \mathrm{~N} 1$ pandemic, between $62 \%$ and $85 \%$ of those who died were younger than 65 .

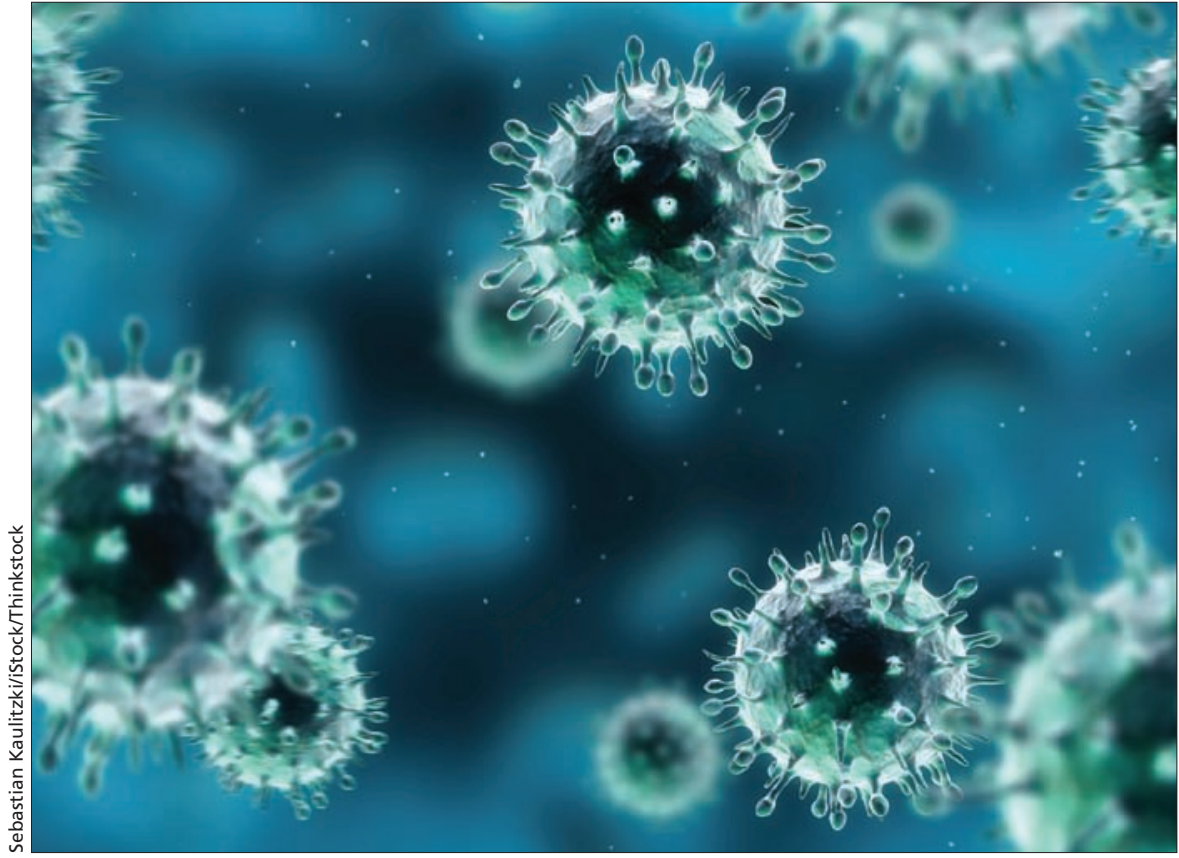

As of Jan. 13, there were 26 confirmed deaths across Canada due to Type A (H1N1) flu virus.

The prevalence of Type A (H1N1) influenza this year is worst in Western Canada, from Saskatchewan to British Columbia, says Dr. Michael Gardam, director of Infection, Prevention and Control at the University Health Network in Toronto, Ont. "However, they're all through the peak. The worst of it is done."

In Canada, seasonal flu normally contributes to approximately 20000 hospital admissions and between 4000 and 8000 deaths annually.

During the H1N1 pandemic in 2009, the virus caused more than 284000 deaths worldwide, according to the US Centers for Disease Control and Prevention. At that time, the World Health Organization declared H1N1 a pandemic virus. However, the virus is now circulating like a seasonal influenza virus.

"We had tons of H1N1 in 2009 and then the last two flu seasons has been predominantly $\mathrm{H} 3 \mathrm{~N} 2$, with not much H1N1," says Gardam. "This year, H1N1 has shown up in Canada. However, if you look at Europe, it's still H3N2. It gives an example of how you never know what the flu is going to do."

Doctors are using antivirals to lessen symptoms in high-risk patients, such as those with compromised immune systems, says Gardam. However, antivirals are not being used for low-risk patients owing to concerns about the development of resistance to antivirals.

Alberta confirmed a death on Jan. 8, due to the virus H5N1, an avian virus. The deceased woman had recently returned from China. The mortality rate is higher with $\mathrm{H} 5 \mathrm{~N} 1$ than $\mathrm{H} 1 \mathrm{~N} 1$, "but fortunately, it's not an easy virus to transmit," says Lebel. So far, it seems that there are no cases of $\mathrm{H} 5 \mathrm{~N} 1$ transmission from human-to-human. It seems like the cases of $\mathrm{H} 5 \mathrm{~N} 1$ are few and far between and related to contact with birds in China. — Patrick Janukavicius, Montréal, Que.

CMAJ 2014. DOI:10.1503/cmaj.109-4701 